\title{
Seroprevalence of Toxoplasma gondii infection from water buffaloes (Bubalus bubalis) in northeastern and southern Thailand
}

\author{
Tawin Inpankaew ${ }^{1 *}$, Thi Thuy Nguyen ${ }^{1,2}$, Burin Nimsuphan ${ }^{1}$, Chanya Kengradomkij $^{1}$, Ketsarin Kamyingkird ${ }^{1}$, \\ Wissanuwat Chimnoi ${ }^{1}$, Boy Boonaue ${ }^{1}$ and Xuenan Xuan ${ }^{3}$
}

\author{
${ }^{1}$ Department of Parasitology, Faculty of Veterinary Medicine, Kasetsart University, Bangkok, Thailand; \\ ${ }^{2}$ Faculty of Animal Science and Veterinary Medicine, University of Agriculture and Forestry, Hue University, Hue City, Vietnam; \\ ${ }^{3}$ National Research Center for Protozoan Diseases, Obihiro University of Agriculture and Veterinary Medicine, Inada-cho, Obihiro, \\ Hokkaido, Japan
}

\begin{abstract}
Toxoplasmosis is a parasitic disease resulting from infection with the apicomplexan Toxoplasma gondii (Nicolle et Manceaux, 1908), one of the world's most common parasites in warm-blooded animals, including humans. Sources of infection can be exposed to infected cat faeces, mother-to-child transmission during pregnancy, and notably, the consumption of undercooked contaminated meat of intermediate hosts. In Thailand, water buffaloes are highly valued for rice cultivation, traditional culture and meat production. Like several other mammalian species, these animals play a role as reservoirs of $T$. gondii, thus representing a threat to human health. The seroprevalence of $T$. gondii infection in swamp buffaloes was examined in southern and northeastern Thailand. In total, serum samples of 721 water buffaloes were collected from seven provinces (Ubon Ratchathani, Roi Et, Si Sa Ket, Surin, Buri Ram, Sakon Nakhon, and Songkhla) and examined for the presence of $T$. gondii infection using commercial latex agglutination test kits (TOXOCHECK-MT, Eiken Chemical Co., Tokyo, Japan). Of the 721 animals analysed, 49 (6.8\%) were positive for $T$. gondii. Songkhla province had the highest seroprevalence (14.7\%) among the seven provinces covered in this survey. There was a potential risk to local citizens of $T$. gondii infection identified by the present study, notably in northeastern Thailand, where despite lower seroprevalence consuming raw buffalo meat salad should be restricted to avoid the risk of zoonotic infections.
\end{abstract}

Keywords: Toxoplasmosis, zoonoses, serodiagnosis, latex agglutination test.

Toxoplasma gondii (Nicolle et Manceaux, 1908) is an obligate intracellular protist (Apicomplexa) causing toxoplasmosis in a vast array of warm-blooded animals, including humans and livestock. Felids serve as definitive hosts of the parasite, whereas other animals are considered as its intermediate hosts (Taylor et al. 2015). One-third of the global population has been estimated to be infected with this parasite (Halonen and Weiss 2013).

One of the main routes for human infection by $T$. gondii is the consumption of raw or undercooked meat of infected intermediate hosts, containing tissue cysts (Tenter et al. 2000, Kijlstra and Jongert 2008, Tenter 2009, Robert-Gangneux and Dardé 2012, Belluco et al. 2018, Pinto-Ferreira et al. 2019). Cysts have been isolated and detected from $3-22 \%$ of fresh and frozen buffalo meat samples obtained from retail stores, makets and abbatoirs in many regions (Chaudhary et al. 2006, El-Tras et al. 2012, Gencay et al. 2013, Bărburaș et al. 2019). Therefore, the disease is considered to be a public health issue in areas where beef has been destined for broadscale human consumption (Gomes et al. 2020). In northeastern Thailand, a so-called Sachin salad made from raw buffalo meat has been commonly eaten with local liquors, thereby raising serious concerns about human infection among native dwellers (Lanna Food 2014).

The fact that toxoplasmosis in buffaloes and cattle is mostly subclinical impairs the detection of the disease when it is based only on the observation of its clinical manifestation. Thus, the use of laboratory-based approaches that provide data on the prevalence of $T$. gondii infection in these animals is the only way to assess the risk of transmission to humans through the consumption of raw and undercooked meat (Dubey 2010). While mouse bioassay is the gold standard to isolate the parasite from tissue, numerous serological techniques have been used worldwide to determine the seroprevalence of $T$. gondii infection (Dubey 2010, de Barros et al. 2020). 
Table 1. Seroprevalence of Toxoplasma gondii (Nicolle et Manceaux, 1908) infection in water buffaloes based on latex agglutination test.

\begin{tabular}{|c|c|c|c|c|c|c|c|}
\hline Province & $\begin{array}{c}\text { No. } \\
\text { tested }\end{array}$ & $\begin{array}{c}\text { No. } \\
\text { positive (\%) }\end{array}$ & $1: 64$ & $1: 128$ & $\begin{array}{c}\text { Titre } \\
1: 256\end{array}$ & $1: 512$ & $1: 1,024$ \\
\hline \multicolumn{8}{|l|}{ North-eastern } \\
\hline Ubon Ratchathani & 138 & $9(6.5)$ & 7 & 1 & 1 & 0 & 0 \\
\hline Roi Et & 81 & $9(11.1)$ & 7 & 1 & 0 & 0 & 1 \\
\hline Si Sa Ket & 59 & $2(3.4)$ & 1 & 1 & 0 & 0 & 0 \\
\hline Surin & 73 & $4(5.5)$ & 2 & 2 & 0 & 0 & 0 \\
\hline Buri Ram & 70 & $1(1.4)$ & 0 & 1 & 0 & 0 & 0 \\
\hline Sakon Nakhon & 205 & $10(4.9)$ & 6 & 3 & 1 & 0 & 0 \\
\hline Total (\%) & 626 & $35(5.6)$ & $23(65.7)$ & $9(25.7)$ & $2(5.7)$ & 0 & $1(2.9)$ \\
\hline \multicolumn{8}{|l|}{ Southern } \\
\hline Songkhla (\%) & 95 & $14(14.7)$ & $3(21.4)$ & $4(28.6)$ & $4(28.6)$ & $2(14.3)$ & $1(7.1)$ \\
\hline Total (\%) & 721 & $49(6.8)$ & $26(53.1)$ & $13(26.5)$ & $6(12.2)$ & $2(4.1)$ & $2(4.1)$ \\
\hline
\end{tabular}

Buffaloes hold great significance not only in the agricultural system in Asian countries but also in providing meat and milk which have been recognised as healthy products with appropriate essential components for humans (Wanapat and Chanthakhoun 2015). In Thailand, considering the significantly declining numbers (Department of Livestock Development 2017), buffaloes have been specifically raised for multi-purposes of draft, manure, money-saving, and calf and meat production in integrated farming in the northeast and the south. The buffaloes and cattle are traditionally grazed on paddy field or grassland during the daytime and are supplemented with rice straw at night or when confined (Uriyapongson 2013). Consequently, they are likely to get infected due to the nature of grazing in an environment contaminated with the sporulated oocysts that are transported by water flow, or transport and reservoir hosts (Andreoletti et al. 2007, de Barros et al. 2020). Indeed, antibodies to T. gondii were found in $26 \%$ of tested beef cattle in the west (Wiengcharoen et al. 2012), 15\% in Kanchanaburi, Ratchaburi, and Nakhon Pathom provinces (Udonsom et al. 2018); and in $9-17 \%$ of dairy cows from the northeast (Inpankaew et al. 2010). Therefore, the current study aimed to investigate the seroprevalence of $T$. gondii infection in water buffaloes from northeastern and southern Thailand.

\section{MATERIALS AND METHODS}

\section{Sample collection}

The water buffaloes selected were typically raised under an integrated agricultural system, whereby small-holders generally own only 2-4 animals (the northeast), and medium-holders raise 10 or more animals (the south). They are destined mainly for meat products and ploughing rice fields.

A sample size of 574 buffaloes was determined using the formula in ProMESA 2.3 (2011): estimated sample size - simple random sample $(n)=p \times(1-p) \times z^{2} / e^{2}$, where $p$ (expected prevalence $)=14.33 \%$ (Hamidinejat et al. 2010), $\mathrm{z}$ is the confidence level (95\%), and e is the acceptable relative error (0.2). However, the actual sample size was greater than the estimated values as 712 buffaloes were conveniently collected in June (the rainy season) from seven provinces. Six of the provinces (Ubon Rachathani, Roi Et, Si Sa Ket, Surin, Buri Ram, and Sakon Nakhon) are in the northeast and have a tropical savanna climate. The mean annual rainfall and temperature in this area are about $1501 \mathrm{~mm}$ and $27.8^{\circ} \mathrm{C}$, respectively. Another province (Songkhla) is in the south and has a tropical monsoon climate, with a mean annual rainfall of 1703-3494 mm, and a mean annual temperature of $28.3^{\circ} \mathrm{C}$ (Thai Meteorological Department 2017). The number of farms and samples in each province was based on the buffalo population size, accessibility to ranches or natural pastures raising buffaloes, and the owners' acceptance of sampling (Fig. 1).

The blood samples were collected from the caudal vein of the water buffaloes using $10 \mathrm{ml}$ blood collection tubes without anti-coagulant (Meus SRL, Piove di Sacco, Italy). In the laboratory, each sample was centrifuged at $1448 \mathrm{~g}$ for 15 minutes before the serum fraction was removed and stored at $-20^{\circ} \mathrm{C}$ until serological analysis. In addition, demographic data were also collected using a checklist during the blood sample collection, consisting of age (49 animals aged less than 1 year, 432 aged $1-5$ years, and 240 animals aged more than 5 years); the reproductive period was used to categorise the animals in age as described by Jainudeen (2002), gender (107 males and 614 females), and region ( 626 buffaloes from the northeast and 95 from the south).

This study adhered to the Guidelines of Animal Care and Use under the Ethical Review Board of Obihiro University of Agriculture and Veterinary Medicine (Permit for animal experiment No. 290131).

\section{Serological assay}

Antibodies to Toxoplasma gondii in all serum samples were detected using commercial latex agglutination test (LAT) kits (TOXOCHECK-MT, Eiken Chemical Co., Tokyo, Japan) as previously described (Inpankaew et al. 2010). Each sample was screened in a series of dilutions of $1: 16,1: 32,1: 64,1: 128$, $1: 256,1: 512,1: 1,024$, and $1: 2,048$ in U-shaped 96-well cluster plates (Nalge Nunc, New York, USA). An amount $(25 \mu \mathrm{l})$ of latex agglutination buffer was coated in every well before $25 \mu 1$ of $1: 8$ diluted serum was added to the first well. Two-fold serial dilutions then were performed and the final $25 \mu$ of the mixture was discarded. Finally, $25 \mu 1$ of $T$. gondii-coated latex beads were added to each well. The plates were gently shaken and incubated at room temperature overnight. The LAT was considered positive when agglutination was observed at dilutions of $1: 64$ or above according to the manufacturer's instruction.

\section{Statistical analysis}

Statistical analysis was conducted using the $\mathrm{R}$ version 3.6.3 software (R Core Team 2020). Statistically significant differences 


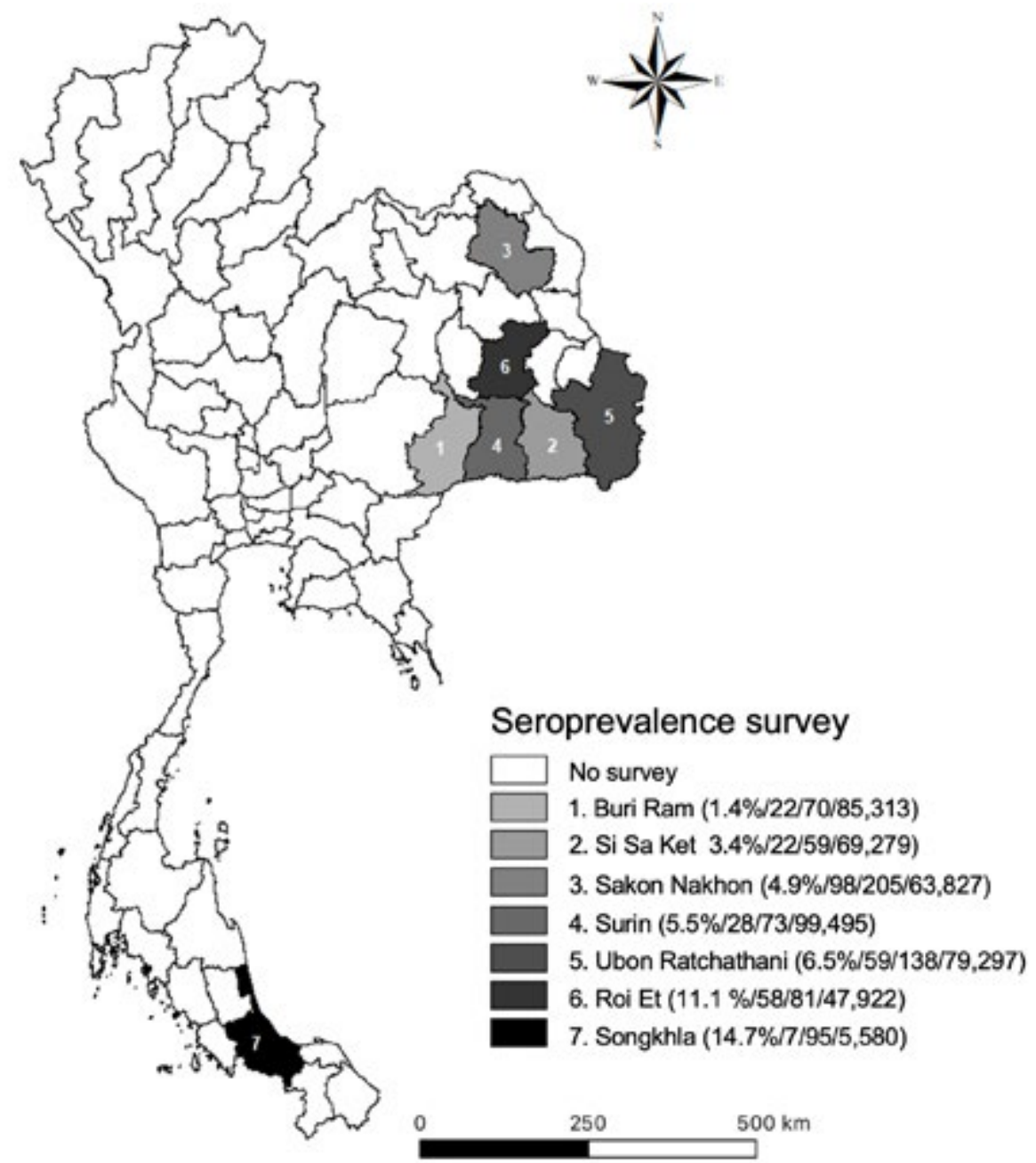

Fig. 1. Epidemiological seroprevalence of Toxoplasma gondii (Nicolle et Manceaux, 1908) in water buffaloes from northeastern and southern Thailand. Figures in parentheses are seroprevalence/number of farms/number of samples/population size.

between the frequencies of groups were considered at $p<0.05$ using a $\chi^{2}$ test and Fisher's exact test.

\section{RESULTS}

\section{Seroprevalence of Toxoplasma gondii}

In general, antibodies to Toxoplasma gondii were found in $49(6.8 \%)$ of the 721 serum samples screened using LAT. In northeastern Thailand, T. gondii infection was most prevalent (11.1\%) among buffaloes raised in Roi Et Province, while the lowest prevalence value observed was $1.4 \%$, in Buri Ram Province. Seroprevalence in buffaloes from Surin and Sakon Nakhon was similar at 5.5\% and $4.9 \%$, respectively. There was a seroprevalence of $3.4 \%$ in buffaloes from Si Sa Ket and $6.5 \%$ of buffaloes in Ubon Rachathani were infected with $T$. gondii (Fig. 1).

The majority of the samples for $T$. gondii presented low LAT titres. The most common titre was $1: 64$ (66\% of the positive samples). The remaining $25 \%$ of samples corresponded to the titre $1: 128$. Only one and two positive samples showed $1: 1,024$ and $1: 256$ titres, respectively. No sample was positive at the moderate titre of $1: 512$ (Table 1). In Songkhla province, titres of either $1: 128$ or $1: 256$ accounted for $28.6 \%$ of positive serum samples.
While $21 \%$ of positive sera were recorded for the $1: 64$ titre, only one and two were observed in $1: 1,024$ and $1: 512$ titres, respectively (Table 1 ).

Of the 294 farms, 39 had serological evidence of $T$. gondii infection (13.3\%). They were widely distributed among all investigated provinces: Ubon Rachathani (8/59, 14\%), Roi Et (9/58, 16\%), Si Sa Ket (2/22, 9\%), Surin (4/28, $14 \%)$, Buri Ram (1/22, 5\%), Sakon Nakhon (9/98, 9\%), and Songkhla $(6 / 7,86 \%)$.

Considering age, only $2 \%$ of the calves (aged less than 1 year) were positive for $T$. gondii infection, whereas buffaloes aged $1-5$ years and buffaloes older than 5 years presented prevalence values of $6.3 \%$ and $8.7 \%$, respectively. The prevalence of infection was $3.8 \%$ for male buffaloes and $7.3 \%$ for the females. However, these differences in prevalence values were not significant (Table 2$)$. The seroprevalence of the disease was significantly $(p=0.002)$ higher in water buffaloes from the southern province $(14.7 \%)$ than from the provinces in the northeast $(5.6 \%)$ (Table 2).

\section{DISCUSSION}

The seroprevalence observed in all selected provinces showed the wide distribution of Toxoplasma gondii in wa- 
Table 2. Seroprevalence of Toxoplasma gondii (Nicolle et Manceaux, 1908) infection in water buffaloes based on age, sex and area.

\begin{tabular}{|c|c|c|c|c|c|}
\hline Variable & & No. tested & No. positive & Prevalence & $p$ value \\
\hline \multirow{3}{*}{ Age (years) } & $<1$ & 49 & 1 & 2.0 & \multirow{3}{*}{0.20} \\
\hline & $1-5$ & 432 & 27 & 6.3 & \\
\hline & $>5$ & 240 & 21 & 8.7 & \\
\hline \multirow{2}{*}{ Sex } & Male & 107 & 4 & 3.8 & \multirow[t]{2}{*}{0.248} \\
\hline & Female & 614 & 45 & 7.3 & \\
\hline \multirow{2}{*}{ Area } & Northeast & 626 & 35 & 5.6 & \multirow[t]{2}{*}{0.002} \\
\hline & South & 95 & 14 & 14.7 & \\
\hline Total & & 721 & 49 & 6.8 & - \\
\hline
\end{tabular}

ter buffaloes located in northeastern and southern Thailand. Infection of water buffaloes with $T$. gondii has been investigated worldwide in many continents, with prevalence ranging from 0 to $88 \%$ reported using different serological techniques (de Barros et al. 2020). The seroprevalence in the present study was lower than those of some investigations carried out in buffaloes from other Asian countries, such as $14 \%$ in Iran (Hamidinejat et al. 2010), 14\% in Pakistan (Anees et al. 2014) and 18\% China (Luo et al. 2017), but higher than that of $3 \%$ in India and Vietnam (Huong et al. 1998, Sharma et al. 2008).

Previous studies demonstrated that transmission and distribution of $T$. gondii among buffaloes could be associated with some climatic factors, notably rainfall and temperature (Yan et al. 2016, de Barros et al. 2020). Overall, the worldwide prevalence of $T$. gondii infection in humid tropical areas is generally higher than in hot and dry areas, and cooler areas (Tenter et al. 2000). Precipitation is very important in transporting water-borne pathogens in a terrestrial environment (Gotteland et al. 2014). Indeed, substantially increased river flow due to annual rainfall events can deliver $T$. gondii oocysts from the land to water bodies, leading to water-borne toxoplasmosis and high levels of coastal contamination with this protozoan parasite (Karanis et al. 2012, Mazzillo et al. 2013, Ribeiro et al. 2015). In addition, a moist environment created by rain enables sporulated oocysts to prolong their survival in the soil and grass for several years, thus increasing the opportunities for buffaloes to become exposed to oocysts when feeding on pasture (Dubey and Beattie 1988, Gubler et al. 2001).

Temperature is another key environmental factor considerably impacting the distribution of $T$. gondii (see Yan et al. 2016). A $0.6^{\circ} \mathrm{C}$ increase in temperature was positively correlated with an increased prevalence of human toxoplasmosis (Caballero-Ortega et al. 2012). Apparently, high mean annual temperatures and precipitation could result in increased abundance of insect species (as transport hosts) which can carry oocysts on their exoskeleton (Graczyk et al. 2001), or of rodents considered as reservoir hosts for T. gondii (see Kijlstra et al. 2008). Therefore, there is an increased risk that they transfer the parasite to cats and livestock animals (Meerburg and Kijlstra 2009, Yan et al. 2016).

Thailand is located in the tropical geographical zone and has a tropical climate. The country has distinct climatic variations between the northeast (tropical savanna) and the south (tropical monsoon) (Thai Meteorological Department 2017). It is likely that the hot and humid climate in the south provides better conditions than the colder and drier climate in the northeast to support the circulation of T. gondii in the natural environment. However, due to the potential for bias introduced by discrepancies in sampling in the present study, further ecological modelling is needed to evaluate the climatic factors relating to $T$. gondii infection in buffaloes from the two studied regions.

In Thailand, seroprevalence of $T$. gondii has been studied and updated in a range of hosts, such as stray cats (Jittapalapong et al. 2010, Kengradomkij et al. 2018, Huertas-López et al. 2021), stray dogs (Jittapalapong et al. 2009, Huertas-López et al. 2021), beef cattle (Wiengcharoen et al. 2012, Udonsom et al. 2018), and free-range chickens (Saichua et al. 2017). To the best of our knowledge, the present study is the first report of $T$. gondii seroprevalence in buffaloes in the country, revealing a considerable risk of infection for humans from these animals. Indeed, one of the most popular salads in the northeastern Thailand is 'sa chin', which is made with sliced raw buffalo meat freshly slaughtered in the early morning without any well-cooked processing, and then usually consumed with native liquor (Lanna Food 2014). Together with the diverse genotypes found in cat faeces in the country (Buddhirongawatr et al. 2016, Chemoh et al. 2018), this eating custom introduces a potential source of $T$. gondii infection among local communities.

Seropositive buffaloes were identified in 39 of the 294 farms, which suggests that humans and animals living on those farms may be exposed to infection. Furthermore, higher seroprevalence was found in older buffaloes. This increasing prevalence with age could have been due to the older animals having a longer exposure to the parasite, especially in integrated farming where the buffaloes freely graze on contaminated grasslands or waterbodies (Bărburaș et al. 2019). In the integrated systems in Thailand, female buffaloes are commonly raised for calf and meat production, ploughing rice fields, manure, money-saving, and family heritage, and then slaughtered at the end of their productive life. Therefore, the females are invariably older than the males (Uriyapongson 2013), which may lead to a general tendency for female buffaloes to be more heavily infected than males. However, the risk factors related to gender and age could not be evaluated in the present study due to the discrepancies in sampling.

In conclusion, a moderate seroprevalence of $T$. gondii infection in buffaloes was found in northeastern and southern Thailand compared with other investigated countries in Asia, revealing the potential risk for human infection with T. gondii from buffaloes. Although the northeast area had a lower prevalence, the local community members there could become infected by consuming traditional raw beef salad. Oocyst-contaminated water, soil and grass in grasslands or pastures may be responsible for the infection of the buffaloes. Because of the present study's limitations (discrepancy in sample size, a lack of information about crucial risk factors during sampling), further research is necessary to determine the source of infection and to as- 
sess the risk factors for $T$. gondii transmission in the buffalo population in the country.

Acknowledgements. The provincial veterinary officers of the Department of Livestock Development in Ubon Ratchathani, Roi Et, Si Sa Ket, Surin, Buri Ram, Sakon Nakhon, and Songkhla provinces provided support in collecting blood samples from water buffaloes. This project was financially supported by the Faculty of Veterinary Medicine, Kasetsart University, Bangkok, Thailand (grant number 62_05), and the Kasetsart University Research Development Institute (KURDI) grant number 33.56.

\section{REFERENCES}

Andreoletti O., Budka H., Buncic S., Colin P., Collins J.D., De A., VÅgsholm I. 2007: Surveillance and monitoring of Toxoplasma in humans, food and animals. Scientific Opinion of the Panel on Biological Hazards. EFSA J. 583: 1-64.

Anees A., Maqbool A., Khan U.J., Yasmin G., Zahra F. 2014 Seroprevalence of antibodies to Toxoplasma gondii in butchers and buffaloes at Lahore, Pakistan. Pakistan J. Zool. 46: 14791483.

Bărburaş D., Györke A., Blaga R., Bărburaş R., Kalmár Z., Vişan S., Mircean V., Blaizot A., Cozma V. 2019: Toxoplasma gondii in water buffaloes (Bubalus bubalis) from Romania: what is the importance for public health? Parasitol. Res. 118: 2695-2703.

de Barros L.D., Garcia J.L., Bresciani K.D.S., Cardim S.T., Storte V.S., Headley S.A. 2020: A review of toxoplasmosis and neosporosis in water buffalo (Bubalus bubalis). Front. Vet. Sci. 7: 455 .

Belluco S., Simonato G., Mancin M., Pietrobelli M., Ricci A. 2018: Toxoplasma gondii infection and food consumption: a systematic review and meta-analysis of case-controlled studies. Crit. Rev. Food Sci. Nutr. 58: 3085-3096.

Buddhirongawatr R., Chaichoun K., Tungsudjai S., Udonsom R., Thompson A., Mahittikorn O., Dekumyoy P. 2016: Seroprevalence and phylogenetic analysis of Toxoplasma gondii from domestic cats, captive wild felids, free-range wild felids and rats in certain regions of Thailand. Thai Vet. Med. 46: 209-218.

Caballero-Ortega H., Uribe-Salas F.J., Conde-Glez C.J., Cedillo-Pelaez C., Vargas-Villavicencio J.A., LUna-Pastén H., Cañedo-Solares I., Ortiz-Alegría L.B., Correa D. 2012: Seroprevalence and national distribution of human toxoplasmosis in Mexico: analysis of the 2000 and 2006 National Health Surveys. Trans. R. Soc. Trop. Med. Hyg. 106: 653-659.

Chaudhary Z., Ahmed R., Hussain S., Shakoori A. 2006: Detection of Toxoplasma gondii infection in butchers and buffaloes by polymerase chain reaction and latex agglutination test. Pakistan J. Zool. 38: 333.

Chemoh W., Sawanguaroen N., Nissapatorn V., SermwitTAYAWONG N. 2018: Genotyping of Toxoplasma gondii isolated from cat feces in Songkhla, southern Thailand. Vet. Parasitol. Reg. Stud. 13: 105-109.

Department of Livestock Development. 2017: Number of livestock inventory in Thailand in 2017. http://en.dld.go.th/ index.php/en/statistics-menu/statistics-livestock-in-thailand-menu/190-number-livestock2017.

Dubey J.P. 2010: Toxoplasmosis of Animals and Humans. The Second Edition. CRC Press, Boca Raton, $175 \mathrm{pp}$.

Dubey J.P., Beattie C. 1988: Toxoplasmosis of Animals and Man. CRC Press, Boca Raton, 220 pp.

El-Tras W.F., Tayel A.A., El-Kady N.N. 2012: Source diversity of Toxoplasma gondii infection during meal preparation. J. Food Safety 32 : 1-5.

Gencay Y.E., Yildiz K., Gokpinar S., Leblebicier A. 2013 A potential infection source for humans: frozen buffalo meat can harbour tissue cysts of Toxoplasma gondii. Food Control 30: $86-89$.

Gomes D., Krawczak F., Oliveira C., Ferreira Júnior Á., Fernandes É., Lopes W., Seví A., Gennari, S. M. 2020:
Toxoplasma gondii in cattle in Brazil: a review. Rev. Bras. Parasitol. Vet. 29: e015719.

Gotteland C., Gilot-Fromont E., Aubert D., Poulle M.L., Dupuis E., Dardé M.L., Wiart M.A., Rabilloud M., Riche B., Villena I. 2014: Spatial distribution of Toxoplasma gondii oocysts in soil in a rural area: influence of cats and land use. Vet. Parasitol. 205: 629-637.

Graczyk T.K., Knight R., Gilman R.H., Cranfield M.R. 2001: The role of non-biting flies in the epidemiology of human infectious diseases. Microbes Infect. 3: 231-235.

Gubler D.J., Reiter P., Ebi K.L., Yap W., Nasci R., Patz J.A. 2001: Climate variability and change in the United States: potential impacts on vector- and rodent-borne diseases. Environ. Health Perspect. 109 (Suppl 2): 223-233.

Halonen S.K., Weiss L.M. 2013: Toxoplasmosis. Handb. Clin. Neurol. 114: 125-145.

Hamidinejat H., Ghorbanpour M., Nabavi L., Haji HajikOlaie M.R., Razi Jalali M.H. 2010: Seroprevalence of Toxoplasma gondii in water buffaloes (Bubalus bubalis) in south-west of Iran. Trop. Biomed. 27: 275-279.

Huertas-López A., Sukhumavasi W., Álvarez-García G., Martínez-Subiela S., Cano-Terriza D., Almería S., Dubey J.P., García-Bocanegra I., Cerón J.J., MartínEZ-CARRASCo C. 2021: Seroprevalence of Toxoplasma gondii in outdoor dogs and cats in Bangkok, Thailand. Parasitology 148: 843-849.

Huong L.T., Ljungström B.L., UgGla A., Björkman C. 1998: Prevalence of antibodies to Neospora caninum and Toxoplasma gondii in cattle and water buffaloes in southern Vietnam. Vet. Parasitol. 75: 53-57.

Inpankaew T., Pinyopanuwut N., Chimnoi W., Kengradomkit C., Sununta C., Zhang G., Nishikawa Y., Igarashi I., Xuan X., Jittapalapong S. 2010: Serodiagnosis of Toxoplasma gondii infection in dairy cows in Thailand. Transbound. Emerg. Dis. 57: 42-45.

JAINUDEEN M.R. 2002: Buffalo husbandry/Asia. In H. Roginski (Ed.), Encyclopedia of Dairy Sciences. Academic Press, San Diego, United States, pp. 186-193.

Jittapalapong S., Inpankaew T., Pinyopanumat N., Chimnoi W., Kengradomkij C., Wongnark pet S., Maruyama S., Leknla A., Sukthana Y. 2010: Epidemiology of Toxoplasma gondii infection of stray cats in Bangkok, Thailand. Southeast Asian J. Trop. Med. Publ. Health 41: 13-18.

Jittapalapong S., Sittisan P., Sakpuaram T., Kabeya H., Maruyama S., InPankaew T. 2009: Coinfection of Leptospira spp. and Toxoplasma gondii among stray dogs in Bangkok, Thailand. Southeast Asian J. Trop. Med. Publ. Health 40: 247-252.

Karanis P., Aldeyarbi H., Mirhashemi M., Ismail K. 2012: The impact of the waterborne transmission of Toxoplasma gondii and analysis efforts for water detection: an overview and update. Environ. Sci. Pollut. Res. Int. 20: 86-99.

Kengradomkij C., Kamyingkird K., Pinyopanuwat N., Chimnoi W., Jittapalapong S., Inpankaew T. 2018: Seroprevalence of Toxoplasma gondii from stray cats residing in temples, Bangkok, Thailand. J. Trop. Med. Parasitol. 41: 8-14.

Kijlstra A., Meerburg B., Cornelissen J., De Craeye S., Vereijken P., Jongert E. 2008: The role of rodents and shrews in the transmission of Toxoplasma gondii to pigs. Vet. Parasitol. 156: $183-190$. 
KiJlstra A., Jongert E. 2008: Control of the risk of human toxoplasmosis transmitted by meat. Int. J. Parasitol. 38: 1359-1370.

LANNA Food 2014: Sa pli - Lanna Food/Northern Thai Information Center, Chiang Mai University Library. Retrieved from https://web.archive.org/web/20141008015634/http://library.cmu. ac.th/ntic/en_lannafood/detail_lannafood.php?id_food $=157$

Luo H., Li K., Z̈hang H., Gan P., Shahzad M., Wu X., Lan Y., WANG J. 2017: Seroprevalence of Toxoplasma gondii infection in zoo and domestic animals in Jiangxi Province, China. Parasite 24: 7 .

Mazzillo F.F., Shapiro K., Silver M.W. 2013: A new pathogen transmission mechanism in the ocean: the case of sea otter exposure to the land-parasite Toxoplasma gondii. PLoS ONE 8: e82477.

Meerburg B.G., KiJlstra A. 2009: Changing climate-changing pathogens: Toxoplasma gondii in north-western Europe. Parasitol. Res. 105: 17-24.

Pinto-Ferreira F., Caldart E.T., Pasquali A., MitsuKa-Breganó R., Freire R.L., Navarro I.T. 2019: Patterns of transmission and sources of infection in outbreaks of human toxoplasmosis. Emerg. Infect. Dis. 25: 2177-2182.

R Core Team 2020. R: a language and environment for statistical computing. R Foundation for Statistical Computing, Vienna, Austria. https://www.R-project.org/.

Ribeiro L.A., Santos L.K., Brito P.A., Jr., Maciel B.M., Da Silva A.V., Albuquerque G.R. 2015: Detection of Toxoplasma gondii DNA in Brazilian oysters (Crassostrea rhizophorae). Genet. Mol. Res. 14: 4658-4665.

Robert-Gangneux F., Dardé M.L. 2012: Epidemiology of and diagnostic strategies for toxoplasmosis. Clin. Microbiol. Rev. 25: 264-296.

Saichua P., Jumnainsong A., Tantrawatpan C., Kiatsopit N., Kopolrat K., Suwannatrai A., Sithithaworn P. 2017: Seroprevalence of Toxoplasma gondii in free range chickens
(Gallus domesticus) in Khon Kaen province, Thailand. Trop. Biomed. 34: 419-424.

Sharma S., Sandhu K.S., Bal M.S., Kumar H., Verma S., Dubey J.P. 2008: Serological survey of antibodies to Toxoplasma gondii in sheep, cattle, and buffaloes in Punjab, India. J. Parasitol. 94: 1174-1175.

TaYlor M.A., Coop R.L., Wall R.L. 2015: Veterinary Protozoology. In: M.A. Taylor (Ed.), Veterinary Parasitology, Fourth Edition. Wiley-Blackwell, New York, pp. 110-160.

Tenter A.M. 2009: Toxoplasma gondii in animals used for human consumption. Mem. Inst. Oswaldo Cruz 104: 364-369.

Tenter A.M., Heckeroth A.R., Weiss L.M. 2000: Toxoplasma gondii: from animals to humans. Int. J. Parasitol. 30: 1217-1258.

Thai Meteorological Department 2017: Annual Weather Summary over Thailand in 2016. https:/www.tmd.go.th/programs/uploads/yearlySummary/weather2016.pdf.

Udonsom R., Sukthana Y., Nishikawa Y., Fereig R.M., Jirapattharasate C. 2018: Current situation of Neospora caninum and Toxoplasma gondii infection among beef cattle in Kanchanaburi, Ratchaburi and Nakhon Patom provinces, Thailand. Thai J. Vet. Med. 48: 403-409.

URIYAPONGSON S. 2013: Buffalo and buffalo meat in Thailand. Buffalo Bull. 32 (Special Issue 1): 329-332.

Wanapat M., Chanthakhoun V. 2015: Buffalo production for emerging market as a potential animal protein source for global population. Buffalo Bull. 34: 169-180.

Wiengcharoen J., Nakthong C., Mitchaothai J., Udonsom R., Sukthana Y. 2012: Toxoplasmosis and neosporosis among beef cattle slaughtered for food in western Thailand. Southeast Asian J. Trop. Med. Publ. Health 43: 1087-1093.

Yan C., Liang L.-J., Zheng K.-Y., Zhu X.-Q. 2016: Impact of environmental factors on the emergence, transmission, and distribution of Toxoplasma gondii. Parasit. Vectors. 9: 137-137.

Cite this article as: Inpankaew T., Nguyen T.T., Nimsuphan B., Kengradomkij C., Kamyingkird K., Chimnoi W., Boonaue B., Xuan X. 2021: Seroprevalence of Toxoplasma gondii infection from water buffaloes (Bubalus bubalis) in northeastern and southern Thailand. Folia Parasitol. 68: 028. 